\title{
The Effect of Hands-on Practice on the Skills Proficiency of Nursing Home Nurses
}

\author{
Dale E. Robbins ${ }^{1}$ \\ ${ }^{1}$ School of Nursing, Bethel University, Mishawaka, Indiana, USA \\ Correspondence: Samuel P. Abraham, Associate Professor of Nursing, Bethel University, 1001 Bethel Circle, \\ Mishawaka, Indiana, USA.
}

Received: February 8, 2020

Accepted: February 20, 2020

Online Published: March 2, 2020

doi:10.20849/ijsn.v5i1.717

URL: https://doi.org/10.20849/ijsn.v5i1.717

\begin{abstract}
Background: The most recent nursing home regulations indicate that nurses must possess the skills sets needed to properly provide residents' care ("Reform of Requirements," 2016). Nursing home directors of nursing (DONs) frequently meet the requirement to train their nurses using online continuing education programs. However, the hands-on practice of fundamental clinical nursing skills necessary to maintain proficiency cannot be accomplished with this method. Purpose: This study aimed to determine whether an educational intervention including hands-on practice of two clinical skills would improve the skills proficiency of nursing home nurses. Method: The study used a pretest-posttest design with skills fair-style educational intervention for nursing home nurses recruited from two nursing homes. The pretest and posttest each included a multiple-choice quiz and hands-on demonstrations of two different clinical skills. Statistical analysis using paired t-tests showed significantly improved skills proficiency for the participating nurses following the educational intervention with hands-on practice of the two clinical skills. Findings: The findings suggest that nursing home DONs should consider educational interventions that include hands-on practice to maintain clinical skills proficiency.
\end{abstract}

Keywords: nursing home nurses, skills proficiency, clinical nursing skills

\section{Introduction}

In the years since the Institute of Medicine published two landmark reports on the status of healthcare in the United States, much emphasis has been placed on prevention of infection and decreasing the number of hospital readmissions (Kohn, Corrigan, \& Donaldson, 2000; Institute of Medicine, 2001). According to Schneider and Ruth-Sahd (2015), many of the measures necessary to do this are the responsibility of nurses who must sharpen their basic, fundamental clinical skills. For the ever-growing population of nursing home residents, nursing home nurses are at the forefront of providing care that can help prevent infection and decrease the number of hospital readmissions for older adults under their care.

Almost $35 \%$ of 16,855 actively licensed LPNs work in long-term care facilities according to the 2012 Indiana Licensed Practical Nurse Licensure Survey Report (Sheff, Zollinger, Harper, Crawford, \& Buente, 2013). In addition, a much smaller percentage of RNs are employed in long-term care. Nursing home residents and their families and friends expect quality care provided by competent nurses. On a regular basis, schools of nursing use local nursing homes as clinical sites for student nurses who often observe LPNs and RNs performing fundamental clinical skills with an assumed high level of proficiency. While nurses are expected to maintain "continued competency" (Indiana General Assembly, 2016b, pp. 2-3), continuing education is not required by the State of Indiana for the renewal of any nursing license (Indiana Professional Licensing Agency, 2018). Employers have a vested interest in the competency of their nurses, usually requiring some amount of annual continuing education (American Nurses Association, 2014). In nursing homes, directors of nursing (DONs) are given the responsibility of training their staff (Indiana General Assembly, 2016a).

\subsection{Statement of Problem}

Current federal nursing home regulations stipulate that nurses have "specific competencies and skill sets necessary to care for residents' needs, as identified through resident assessments, and described in the plan of care" (Reform of Requirements," 2016, pp. 68861-68862). Many online continuing education programs used by nursing home DONs for the mandated training of nurses either do not or are just beginning to include a review or 
updating of clinical nursing skills such as physical assessment, injections, urinary catheterization, or use and care of gastrostomy feeding tubes. However, the hands-on practice necessary to maintain or improve proficiency in the performance of these skills cannot be accomplished with this method. This kind of skills training requires equipment and supplies that can be cost-prohibitive for nursing homes. Nursing home DONs must find ways to assure that their nurses maintain clinical skills proficiency.

\subsection{Purpose of the Project}

The purpose of this Doctor of Nursing Practice (DNP) project was to explore a potential method of providing continuing education nursing home DONs could use to help their nurses maintain or improve clinical skills proficiency. Collaboration with a local school of nursing provided the use of a fully equipped nursing lab as well as nursing instructors who served as observers. Nursing home nurses were evaluated as they demonstrated two clinical skills both before and after completing skills fair-style educational intervention. Emphasis was placed on the psychomotor component of each skill with hands-on practice using the nursing lab models and equipment. Therefore, this project attempted to provide support for the hypothesis that the clinical skills proficiency of nursing home nurses would improve, following an educational intervention emphasizing the hands-on practice of two clinical skills in a school of nursing lab. The project focused on quality improvement in the area of professional development for nursing home nurses.

\subsection{Background}

The terms competent and proficient are often thought to be interchangeable when discussing levels of expertise or ability. Competent is defined as: "having requisite or adequate ability or qualities" or "legally qualified or adequate" ("Competent," 2018, para 2 \& 3), seeming to indicate that one either possesses it or does not. Competence is often discussed in the nursing literature when evaluating senior nursing students', new graduate nurses', or practicing nurses' skills such as time management, critical thinking, cultural understanding, communication, and teamwork and collaboration. Proficient is defined as: "well advanced in an art, occupation, or branch of knowledge" ("Proficient," 2018, para 1), which seems to indicate a gradually increasing process of attainment. Most nursing instructors use the term proficiency and reference Bloom's psychomotor domain when talking about the levels of clinical skills development in first-year through graduating nursing students (Scheckel, 2016). Comparatively, little literature was found, other than nursing education texts, which discussed collective clinical skills or that used the term proficiency. However, for purposes of this project, the term proficiency was used when discussing the changes in the performance of the two clinical skills chosen for this project.

Online continuing education programs specifically for nursing home staff are readily available for purchase by nursing home administrators and DONs. Nursing home DONs commonly require monthly continuing education on assigned topics via the selected online continuing education provider. Important topics related to the care of nursing home residents such as end-of-life care, communication with residents with dementia, health and safety compliance, or infection control are abundant. However, the review or updating of clinical skills for nurses are often not included in the list of available topics or are not included in a list of topics assigned as part of continuing education.

The course listing for EducationInterface (2014) included the categories of "First Aid Training" and "Health and Safety Compliance." Clinical skills listed for nurses were hand hygiene and standard precautions. EasyCEU's course list (n.d.) shows only "Falls and Fractures" as a course that includes the clinical skill of fall risk assessment and nursing interventions associated with it. Relias (2018) does not provide a list of courses but mentions over 200 hours of courses for licensed personnel in areas of compliance and provision of care specific to older adults. Examples provided on the website included courses on dementia care, compliance with beneficiary notices, and quality improvement. On the "Continuing Education Course Search Results" page of the CareCEUs (2018) website for nursing home administrators, the course list for nurses includes multiple courses on topics such as ethics, end of life care, and dementia care. Only two courses, fall prevention, and pain management might contain content that would be considered basic nursing skills. The Proactive Medical Review (2018) website was found to currently include multiple clinical skills for review where it had indicated that a basic nursing skills package was coming soon.

It is possible that the topics the State of Indiana requires for annual review by nursing home nurses may take precedence over basic clinical skills review ("Reform of Requirements," 2016, p. 68870). It is also possible that other online continuing education programs for nurses, not specific to nursing homes, are used. Sites such as Nurse.com (2018), the "Continuing Education" page of the American Nurses Association (n.d.), and the "Nursing Continuing Education Activities: CEConnection" page of the Lippincott Nursing Center website 
(2018) list multiple continuing education courses for nurses. But even the titles of courses on those sites do not indicate a review of many basic clinical skills. Even if they did, online programs could not provide hands-on/psychomotor practice of those clinical skills that require equipment and materials necessary to improve proficiency.

The possibility of a decline in clinical competency and the problems inherent in maintaining it were studied by Wilson, Harwood, and Oudshoorn (2015). They concluded that the perpetual novice phenomenon existed, and described it as a "failure of some nurses to become experts or advance their skills towards expert in one or more nursing skills" (p. 3564). They found that this problem often results from four contributing factors: lack of learning opportunities, lack of support on the nursing unit, poor personal motivation or lack of initiative, and a unit culture where skills acquisition was not highly valued. They also concluded that a decline in skills competency could occur because the nurse lacks the opportunity to use a skill regularly. Although this study took place in acute care settings with registered nurses, long-term care nurses could conceivably exhibit the same decline in clinical skills not used on a regular basis.

The insertion of a urinary catheter is representative of clinical skills taught in nursing education programs and for which nursing home nurses should maintain proficiency. According to the Minimum Data Set 3.0 Public Reports (U. S. Department of Health \& Human Services [HSS], Centers for Medicare \& Medicaid Services [CMS], 2018), $6.21 \%$ of older adults admitted to nursing homes have a urinary catheter in place, and $0.38 \%$ require intermittent catheterization. Urinary catheters increase the risk of urinary tract infections, and catheter-associated urinary tract infections (CAUTI) can be life-threatening (Mody et al., 2015; Castle, Engberg, Wagner, \& Handler, 2017; HHS, Agency for Healthcare Research and Quality [AHRQ], 2017a). The AHRQ oversaw a program for nursing homes that included hands-on training of staff to assure the use of proper catheter insertion techniques and successfully decreased the number of catheter-associated urinary tract infections (HHS, AHRQ, 2017a).

Another clinical skill included in nursing education programs for which nursing home nurses should maintain proficiency in the use and care of gastrostomy feeding tubes. According to the Centers for Medicare and Medicaid Services' Certification and Survey Provider Enhanced Report of January 2014 (as cited by Posthauer, Dorner, \& Friedrich, 2014), approximately $5 \%$ of nursing home residents nationwide were fed via the feeding tube. Complications related to gastrostomy feeding tubes include aspiration pneumonia, buried bumper syndrome, tube dislodgement, local wound infection, and peristomal leakage (Rahnemai-Azar, Rahnemaiazar, Naghshizadian, Kurtz, \& Farkas, 2014). These complications can often be prevented with proper nursing care. Shipley, Gallo, and Fields (2016) and Hayes and Hayes (2018) primarily discussed best practices related to treatment for the common complication of a clogged feeding tube and concluded that the education of nurses is needed to maintain gastrostomy feeding tubes properly.

\section{Clinical Skills Used in This Project}

Two fundamental clinical skills - 1) urinary catheterization and 2) the use of gastrostomy tubes for feeding and medication administration - were chosen to represent fundamental clinical nursing skills for this scholarly project. The literature was searched to find the most current evidence-based practice and information from experts for incorporation into the educational intervention. What follows is a review of the literature related to these two skills that supported the educational information and methods used in this project.

\subsection{Urinary Catheterization}

Reducing catheter-associated urinary tract infections (CAUTIs) in long-term care remains part of the Agency for Healthcare Research and Quality (AHRQ) Safety Program for Long-Term Care (HHS, AHRQ, 2017a). In May of 2017, the AHRQ published a final report on the results of a nationwide project to develop a program to reduce CAUTIs in long-term care. The project provided educational materials for long-term care nursing staff which included the hands-on practice of the urinary catheterization skill. The effectiveness of the project was shown by a decrease in CAUTIs in the nursing homes involved in the project. Among the materials developed during this project were two guides for implementing and sustaining this program in long-term care facilities (HHS, AHRQ, 2017b; HHS, AHRQ, 2017c). Accompanying the implementation guide was a checklist meant to be completed by a trained "technique reviewer." This second nurse was to ensure that the correct steps were followed using the aseptic technique during urinary catheter insertion. The checklist specified leaving an incorrectly placed catheter in the vagina until a new catheter is correctly placed.

The skill of urinary catheterization should be performed in the same manner in any clinical setting. Other research in acute care settings described similar quality improvement efforts to reduce CAUTIs by requiring a second person to observe for proper technique (Belizario, 2015; Rhone et al., 2017) and by no longer pretesting the catheter balloon before insertion (McDevitt \& McDevitt, 2015). Rhone et al. (2017) described checking off 
all nursing staff for competency in performing urinary catheterization with return demonstrations.

McDevitt and McDevitt (2015) noted the Centers for Disease Control and Prevention (CDC) recommends regular continuing education on proper urinary catheter insertion techniques. Jump et al. (2018) reported: "interactive educational modules" (p. 801) were used to provide evidence-based continuing education for long-term care nurses. The result of this effort showed a $31 \%$ reduction in clinician-diagnosed CAUTI.

Kaur, Stone, Travers, Cohen, and Herzig (2017) found training on infection prevention techniques, especially related to CAUTI, was most beneficial to nursing home nurses if it occurred during new-employee orientation and whenever outbreaks of infection occurred. They noted that multiple educational opportunities rather than just one single event were more effective.

Of interest for this project was Battick's (2018) research using simulation and a skills checklist to improve the aseptic insertion techniques of practicing nurses. RNs from an acute care facility demonstrated the skill of urinary catheterization using a task trainer, attended an educational program on proper techniques that included the hands-on practice of the skill, and then demonstrated the skill again. During the pre-intervention and post-intervention demonstrations, a standardized skills checklist was used by observers assessing the demonstrations. Battick found that this method of intervention was successful in improving the skill of the nurses, provided for the more standardized performance of the skill, and could be a cost-saving method for nursing homes.

\subsection{Use and Care of Gastrostomy Tubes}

In a review for the American Society for Parenteral and Enteral Nutrition, Posthauer et al. (2014) discussed the risk for aspiration pneumonia associated with the use of percutaneous endoscopic gastrostomy (PEG) tubes in older adult residents in healthcare communities. They recommended that facilities have routine protocols that include keeping the head of the bed raised at least 30 degrees, proper handwashing and use of clean equipment, routinely monitoring gastric residual volume (GRV), and confirming placement per facility policy. They recommend that the resident be monitored for changes in condition, feeding tolerance, and nutritional status. Peterson (2016) explained the legal aspects of cases where death resulted from aspiration pneumonia and acknowledged that aspiration might occur despite nurses following safe practices.

The finding of Adair et al. (2014) that one of the five skills new BSN graduates rated themselves as least confident in performing was intermittent gastric gavage or bolus feeding was of particular interest to this project. A research study evaluating an educational intervention to increase long-term care nurses' knowledge of gastrostomy tube maintenance, including ways to prevent a clogged tube and the need for replacing it, was described by Shipley et al. (2016). Blumenstein, Shastri, and Stein (2014) explained that clogged feeding tubes often result from the administration of thick nutritional formulas, bulking agents, and medications through narrow diameter PEG tubes. Roulet and Benoit (2016) argued that combining crushed medications in a liquid immediately before administration was not problematic in most cases. These Swiss pharmacists claimed that the viscosity of the solution was the most important consideration when administering medication and trying to avoid clogging the tube. Hayes and Hayes (2018) discussed how nurses should work to prevent clogged tubes and explained best practices for keeping the tube clear. They also described two approved methods to attempt unclogging a tube. Warm water was recommended, but pancreatic enzymes may be used if a provider's order can be obtained.

Major complications of PEG tubes discussed in the literature include buried bumper syndrome, aspiration, dislodgment, misconnections to the tube, internal organ injury, and necrotizing fasciitis (Simons \& Remington, 2013; Rahnemai-Azar et al., 2014; Blumenstein et al., 2014). These same authors also described minor complications such as superficial infection, leakage, clogged tubes, granulation tissue formation, and diarrhea. Of interest to this project was the fact that many of the interventions the authors recommended to prevent these complications can be performed by nurses. In particular, Simons and Remington (2013) described best practices for nurses when caring for individuals with PEG tubes. They explained the need for routine checking of gastric residual volume (GRV), but that assessing for placement is not needed for PEG tubes once placed.

Concerns related to the replacement of dislodged PEG tubes were discussed by Lohsiriwat (2013). He explained several potentially serious complications that could result if the replacement is done incorrectly and not confirmed properly. He described three principles that improve the safety of PEG tube replacement: 1) careful replacement in the tract that is well-healed, 2) use of minimal force during replacement and 3) reliable methods to confirm correct placement - ideally an x-ray with contrast or an upper endoscopy. Severe complications such as peritonitis can be life-threatening, so the replacement of a dislodged tube should not be taken lightly. 
McGinnis (2013) addressed a question about whether nurses should replace gastrostomy tubes. She explained that the nurse needs to know the state's nurse practice act, whether this task falls within the standard of care for a nurse. She stated that nurses should receive training in this procedure since it is not taught in nursing education programs. She reminded nurses that protocols should be developed so that qualified nurses can safely perform this procedure.

Lohmann et al. (2015) described the development and implementation of methods to decrease medication preparation errors in patients with feeding tubes. They wanted nurses to avoid the crushing of medications that should not be crushed. The efforts of Lohmann et al. (2015) were successful in reducing the number of errors, especially with potentially hazardous medications. They also found that most of the errors resulted from the prescription of medications not suited to administration via feeding tubes.

\section{Significance and Impact of the Project}

The anticipated accessible population for this project included approximately 75-80 nurses, based on data on four northern Indiana nursing homes from the Nursing Home Compare webpage (HHS, CMS, n.d.). Residents living in nursing facilities whose nurses participated in the hands-on educational training will benefit from improved care as a result of the nurses' updated training and skills practice. Families, friends, and community members might share their appreciation for the improved quality of care which could positively affect the reputation of the nursing homes within the local area.

A strengths, weaknesses, opportunities, and threats (SWOT) analysis revealed other potentially significant outcomes from this project. The interventional skills fair with the hands-on skills review modules developed for the project could be made available to the DONs of the participating nursing homes as well as to the DONs of other area nursing homes for use with their nurses who did not participate. Further collaboration with the school of nursing used for this project and these nursing homes might also be possible. Each module's content could easily be kept updated with the most recent evidence-based practice for that particular nursing skill. Other basic clinical skills modules could also be created and included in the skills fair according to the needs of the area nursing homes and their nurses.

Collaboration with a local school of nursing to use its nursing laboratory and the expertise of its faculty has the potential to improve the quality of professional development for nursing home DONs and their nurses across the state of Indiana and nationwide. This type of relationship could provide cost-savings to the nursing homes which would not have to purchase expensive task trainers models or mannequins for hands-on practice. Since schools of nursing already have models and mid- to high-fidelity mannequins, a collaboration between nursing home DONs and school of nursing could potentially increase the fidelity of simulation available for hands-on skills practice. Schools of nursing working with nursing homes to provide hands-on education may potentially increase enrollment by using the occasion to promote its career advancement opportunities for nurses. Nursing home nurses could benefit from this method of helping to meet the requirement to maintain their competency.

While trying to decrease the incidence of infection and hospital readmission among nursing home residents, DONs must assure that their nurses maintain the clinical skills proficiency necessary to provide quality care that helps to accomplish this goal. Online continuing education for nursing home nurses does not currently focus on clinical skills. Providing a method of continuing education that emphasizes hands-on practice could help to increase the proficiency of nursing home nurses' performance of clinical skills, potentially resulting in decreased rates of infection and a reduction in hospital readmissions. Improved skills proficiency would also improve the overall quality of care provided to the 1.5 million nursing home residents in the United States (HHS, CMS, 2015).

\section{Theoretical Framework}

Adult learning theory, specifically Malcolm Knowles' theory of andragogy, was chosen as the theoretical framework for this scholarly project. Knowles' work is well known to educators from all disciplines, including nurse educators. Six characteristics of adult learners were described by Knowles, Holton, and Swanson (2005). Adult learners are self-directed and take responsibility for their learning, build on life and work experience while learning, and seek opportunities to learn based on need, such as new circumstances or life changes. They are problem-oriented and want to put what they learn into practice to solve problems or accomplish tasks. They need to know why or how the material is relevant to their situation before engaging in the learning process and are more internally than externally motivated to learn.

Knowles' work has been widely used both nationally and internationally in nursing research and education. Brazilian authors Draganov, de Carvalho Andrade, Neves, and Sanna (2013) performed a literature review to investigate the use of andragogy in nursing publications, finding its use relatively new in Brazil, but more 
prominent in the United States. Knowles' theory of andragogy was used by researchers to evaluate the usefulness of an educational program to promote critical thinking skills among nursing students (Pretoruis, Van Dyk, Small, \& Amukugo, 2016), to test its use during preceptorships of senior nursing students (Leigh, Whitted, \& Hamilton, 2015), to analyze the behaviors of postgraduate nursing students during simulation learning experiences (Spies, Seale, \& Botma, 2015), and to evaluate the effectiveness of a course redesigned to specifically meet the needs of mature students (Relf \& Burgess, 2014). Those who have created and revised professional development programs for new nurses, such as intravenous (IV) therapy and blood administration skills (Parchen, Phelps, Johnson, \& Fisher, 2016) or education about a program recognizing nursing excellence (Shepherd \& Harris, 2016), have also made use of Knowles' theory of andragogy.

\subsection{Alignment of the Framework}

The application of Knowles' characteristics of adult learners to this scholarly project occurred during the development of learning modules for review of the selected basic nursing skills. It also influenced the design of the skills fair event where long-term care nurses used the learning modules. Although the primary focus was on hands-on practice aspects of the skills, several methods of instruction were also incorporated into each module in recognition of the nurses' varied learning styles. The skills fair event provided ample opportunity for them to learn at their own pace, allowing for self-directed learning and building on each nurse's prior experience. The skills demonstrations and written quiz administered to the nurses before the skills fair event may have stirred the need to know more about the skills and increased internal motivation to participate and learn. An attempt was made to externally motivate the nurses by promoting competition among the nursing homes for a pizza party, by awarding points toward prizes for tasks completed or intervention quiz scores achieved by each nurse, and by providing an opportunity to enter a drawing for a gift card. After completing the skills fair activities and the second set of demonstrations of each skill, the nurse participants can apply what was learned at their next opportunity in the workplace.

\subsection{Summary of the Framework}

The terms competency and competencies are most often associated with higher-order nursing skills. The focus of this scholarly project was the fundamental clinical skills initially learned in pre-licensure courses. Since the evaluation of those skills is most commonly expressed as a measure of proficiency, the phrase "clinical skills proficiency' was chosen to describe the dependent variable in this project.

The competence fair and using multiple methods of education, including review materials and hands-on practice for retention of clinical skills, are valid ways to provide continuing education. Nursing home nurses face many challenges when asked to attend or complete continuing education programs. Directors of nursing and others developing continuing education programs for nursing home nurses need to investigate collaboration with schools of nursing. Information for evidence-based practice is readily available in the literature, which could be incorporated into continuing education programs involving urinary catheterization and the use and care of gastrostomy tubes. Each of these factors influenced the development of or was incorporated into the educational intervention for this scholarly project.

\section{Method}

\subsection{Design of the Project}

The scholarly project employed a quasi-experimental pretest, post-test design with an intervention. This design was chosen because, although an intervention was included, there was no control group and participants were not randomized (Polit \& Beck, 2014). The independent variable was the review and updating of two clinical skills at a skills fair-style educational intervention which included the hands-on practice of each skill. Urinary catheterization (female) and medication administration and nourishment via gastrostomy tubes were the skills chosen as representative of fundamental clinical skills for this project. The skills fair provided the most current, evidence-based practice information and techniques, including rationales for the methods used. Clinical Nursing Skills \& Techniques, by Perry, Potter, and Ostendorf (2018a), was used to verify the evidence-based practice information and techniques used in this study.

The dependent variable was nursing skills proficiency as measured by scores on a written quiz and two skills demonstration checklists both before and after the intervention. A comparison was made between the scores on the pre-intervention quizzes and checklists and post-intervention quizzes and checklists to determine whether a significant improvement had occurred.

\subsection{Sample}

The participants were a convenience sample of 13 female nurses. They all participated in the pre and posttest. 
The sample included diploma, associate, and bachelor's degree nurses as listed in Table 1.

\subsection{Inclusion and Exclusion}

The target population for this project was a sample of LPNs and RNs who work full- or part-time at one or more of four northern Indiana nursing homes. The DONs for each of these nursing homes were contacted. Three of the DONs responded and met with the project manager. After hearing a description of the project, these DONs agreed to allow the recruitment of their nurses to participate. During two nursing staff meetings at each facility, the project manager presented the skills fair project, explained the need for the nurses' participation, and provided an opportunity for nurses to begin signing up on the sheets provided. After checking staffing levels with each DON, approximately 60 nurses were identified as the actual accessible population.

Promotional posters, signs, and mailbox flyers were placed in each facility beginning one month before the skills fair to recruit nurses who did not attend the staff meetings where the project was presented. Reminder notices were posted one week ahead of the event. Advertised incentives for participation were a pizza party hosted by the project manager for the facility having the largest percentage of its nurses participate, an opportunity for participating nurses at each facility to enter a drawing for a $\$ 25$ gift card, and prizes awarded to each nurse according to points earned during participation in the project. The Institutional Review Board reviewed the DNP project proposal and exempted it from further review.

\subsection{Setting for Pre and Posttest}

All parts of the project took place on the campus of a private college in Indiana. Permission was sought from and granted by the host college for the use of its classroom facilities. Permission was also sought and granted from the dean of the school of nursing at a second private college, which uses the host college as its satellite campus for a BSN nursing program, to use the nursing lab and its equipment, and to recruit nursing instructors at one of the faculty meetings.

The nursing lab was equipped with four beds and other equipment simulating four typical hospital rooms with curtains to provide privacy around each. One mid-fidelity, life-size mannequin occupied each bed. Two mannequins were set up to support the demonstration of gastrostomy tube use, and two others were set up to support the demonstration of female urinary catheterization. Simulated healthcare provider orders and supplies used in the skills of urinary catheterization and administration of nourishment and medications via feeding tube were provided for participants at the bedsides. All pre- and post-intervention demonstrations were performed for observers in the nursing lab. Completion of the written quizzes took place at tables in the center of the lab where observers could monitor participants to maintain testing integrity.

The educational intervention was set up as a skills fair in an adjacent classroom. Balloons and banners decorated the walls and tables. Modules containing materials for review and updating of each skill were set up in stations on tables in the center and along one wall of the room. Skill stations were set up for hands-on practice. Two optional skills stations where the nurses could review pressure ulcer staging and infection control procedures were also set up in the center of the room. What follows is a description of the modules and skill stations provided in the skills fair.

\section{Skills Fair Modules and Skill Stations}

\subsection{Module 1}

The focus of this module was a review of the steps in urinary catheterization (male as well as female). The nurse was asked to read the implementation steps and rationales on the insertion of a straight or an indwelling catheter on pages 876 to 886 in the skills textbook provided (Perry et al., 2018a). The steps were printed with brief words, connected in proper order by colorful yarn strings, presented on a display board.

\subsection{Module 2}

Update or review of recent changes and recommendations in the performance of urinary catheterization were addressed in this module. A question printed on the center of the display board asked the nurse to lift the 'yes' or 'no' paper flap to check the answer to the question of whether catheter balloons should be tested before insertion or not. The nurse was directed to a highlighted area in the skills textbook where the notation is made that inflating the urinary catheter balloon to check for leaks before insertion is no longer recommended (Perry et al., 2018a). Two catheters were provided as visual aids - one brand new with a smooth tip, and one with a once-inflated but since deflated, wrinkled balloon.

Another question on the left panel of the display board asked the nurse to lift one of three flaps to check the answer to a question about what to do if a catheter is inserted and no urine is obtained. A highlighted area in the 
skills textbook reminded the nurse to leave a catheter incorrectly inserted in the vagina in place until a new catheter is correctly inserted. The nurse could also read the comments on the right panel of the display board labeled "Other Recommendations." One printed phrase recommended using a buddy system or having a second trained nurse present to observe for the use of correct techniques while the catheter is being inserted. Marking the catheter bag with the date and time of insertion was the second printed recommendation.

At an adjacent table, the nurse was directed to use a set of 3" x 5 " cards, one step per card, to practice putting the steps for urinary catheterization in order. An answer key was provided so that the nurse could self-evaluate for the correct order.

\section{Hands-on Practice of Female Catheterization Skill Station}

Nurses were encouraged to perform a minimum one-time practice with a mannequin in a hospital bed where all the necessary supplies were provided. A task-trainer model was also available for practice on a nearby table.

\subsection{Module 3}

Review and hands-on practice of checking feeding tube placement were addressed in this module. The four steps in the procedure were listed down the center of the display board. The nurse was asked to read the implementation steps and rationales on verifying feeding tube placement in the skills textbook provided (Perry et al., 2018a, pp. 849-850). A large, clear plastic jar was weighted with stones and filled with lemon juice. A gastrostomy tube was inserted through the secured cover of this jar which served as a model. The nurse was asked to withdraw fluid from the gastrostomy tube with the provided irrigation kit syringe and test the fluid using the $\mathrm{pH}$ paper provided. Although not regularly done with a gastrostomy tube, this procedure might be necessary when replacing a dislodged gastrostomy tube. Information on the right side of the display board suggested that the nurse turn the patient on the left side to reattempt the withdrawal of gastric fluid if none was obtained with the first attempt. Information on the left panel of the display board reminded the nurse that listening to the insertion of an air bolus is not a reliable test for proper placement.

On an adjacent empty table, card sets with one step per card allowed the nurse to practice putting the steps in providing bolus tube feeding in order. An answer key was provided for the nurse to self-evaluate for the correct order.

\subsection{Module 4}

Review and hands-on practice of checking the gastric residual volume were addressed here. The four steps in the procedure were listed down the center of the display board. The nurse was asked to read the implementation steps and rationales for checking the gastric residual volume in the skills textbook provided (Perry et al., 2018a, p. 855). A large clear plastic jar, weighted with stones and filled with water, with a gastrostomy tube inserted through the secured cover, served as a model. The nurse was asked to practice the steps, as listed on the display board, to withdraw fluid from the gastrostomy tube as if checking for gastric residual volume and then returning it. Information on the left and right panels of the display board reminded the nurse to check for provider orders and to check facility policy about managing residual volumes.

\subsection{Module 5}

A review of steps in gastrostomy tube feedings was addressed here. Steps in both bolus and continuous tube feeding were listed down the center of the display board. Information on the right panel of the display board listed four major complications of gastrostomy tubes. The left panel contained a list of five minor complications. The nurse was asked to read a portion of an article, paying particular attention to potential gastrostomy tube complications (Simons \& Remington, 2013, p. 79-81), and complete a short quiz. The eight multiple-choice questions about those complications were created by the project manager. An answer key was made available for the nurse to check the correct answers. Prize points were awarded based on the score achieved on the quiz.

\subsection{Module 6}

A review of medication administration via feeding tubes was addressed here. The steps in medication administration were listed in the center of the display board. The left panel of the display board listed acceptable forms of medication to be administered. The right panel provided information for the nurse as to which medications should not be crushed. Samples of the types of medications that can and cannot be crushed, using imitation pills in a variety of packaging, were grouped on the table as visual aids. A laptop computer was located at the side of the display board. The nurse was instructed to watch a short video clip including a mnemonic to help nurses remember medications that cannot be crushed (RegisteredNurseRN, 2017). 


\subsection{Module 7}

Emphasis on the proper method of dealing with a clogged feeding tube was addressed here. Four liquids that might be used by nurses attempting to unclog feeding tubes were listed in the center of the display board. The nurse was asked to lift the flap beside the one that should be used to find a checkmark for the correct answer or an ' $x$ ' for the incorrect choices. On the left panel, five possible causes of clogged feeding tubes were listed. On the right panel, two recommendations about the replacement of dislodged feeding tubes were listed: replacement by a trained individual and checking for correct replacement with an $\mathrm{x}$-ray or by testing $\mathrm{pH}$ of the withdrawn gastric fluid.

Hands-on Practice of Tube Feeding Skills Station - Nurses were encouraged to perform a minimum one-time practice with a mannequin in a hospital bed where all the necessary supplies were provided.

\subsection{Optional Skill Station 1}

A review of pressure injury staging occurred in this station. The nurse was invited to test knowledge of pressure injury staging by viewing a model and attempting to identify the stages of the numbered injuries on the model. A correct response key supplied by the model's manufacturer was available next to the model (Vata, Inc., n.d.).

\subsection{Optional Skill Station 2}

A review of transmission-based precautions was another option. A poster board chart with nine infectious diseases listed down the left side was on the table. The nurse was challenged to place cards on the chart under headings to indicate the proper type of transmission-based precautions, the type of room needed, and proper personal protective equipment (PPE) that must be worn beside each disease. The nurse could also complete a one-page copy of the chart, attempting to write in the correct answers. An answer key was available for self-evaluation. Prize points were awarded for the nurse providing correct answers for five or more of the nine diseases.

\subsection{Reward and Recognition}

Two optional games were provided for the nurses to enjoy. Prize points were awarded according to their level of success in each one.

\section{Data Collection Instruments and Observers}

The written quiz was composed of 15 multiple-choice questions about urinary catheterization and medication administration and nourishment via gastrostomy tubes taken from skills exams used for several years by the project manager when teaching fundamentals of nursing course. The questions on the pre-intervention form of the quiz were randomly rearranged to create the post-intervention quiz. Since all participants were nurses who have passed nationally-normed NCLEX exams, the reading level of the questions was assumed to be appropriate. The project manager created the checklists of required steps for each skill based on current methods used to validate these skills for the same fundamentals of nursing course. A comparison with published checklists was made to double-check for accuracy (Perry, Potter, \& Ostendorf, 2018b). Portions of the skills demonstration that required information from the observers were scripted at appropriate points in the checklists.

Six nursing instructors and two experienced nurses, recruited to assist in data collection, conducted the observations required for the evaluation of skills demonstrations. The project manager trained each observer in the use of the checklists to provide consistency. Observers were asked to have another observer take over data collection if they determined an emotional, prejudicial, or another issue (i.e., previous knowledge of a participant) could create bias in data collection.

\section{Data Collection}

As each nurse arrived, student assistants asked each one to read and sign a consent form indicating voluntary participation in the project. Each nurse was assigned a unique identification number for anonymous data management and received a large manila envelope in which to place each completed testing instrument. The project manager provided instructions on how to proceed through the testing in the nursing lab before moving to the skills fair intervention.

Beginning in the nursing lab, each nurse met with an observer at a curtained bedside to demonstrate either female urinary catheterization or feeding and medication administration via a gastrostomy tube. After demonstrating one skill, the nurse went on to an observer at another bedside to demonstrate the second skill. The nurse then completed a demographic questionnaire and the written quiz.

After completing the demonstrations and quiz, each nurse was directed to the adjacent classroom for the skills 
fair educational intervention. The project manager instructed each nurse to write down the time of entry and to spend a minimum of one hour engaging in the modular presentations and practice. Emphasis was placed on taking the time to do the hands-on practice of each skill.

After completing the intervention, each nurse was directed to return to the nursing lab to repeat the demonstration and testing process. Except in one instance, different observers were used for the post-intervention demonstrations of the two nursing skills. Each nurse took the post-intervention quiz last. The envelope containing the demographic questionnaire, both quizzes, and the four demonstration checklists were collected from each participant leaving the nursing lab. All were asked not to share what they had seen, done, or learned during the skills fair until the last skills fair was completed.

The project manager determined the number of points earned by each participating nurse based on scores obtained for Module 5's quiz, and the optional PPE activity if completed. These points were added to points for the completion of the written quizzes, the skills demonstrations, and the intervention. Each nurse was allowed to choose from a selection of prizes awarded according to the total number of points earned. Each nurse also entered the drawing for the $\$ 25$ gift card by signing half of an index card and placing it into one of three sealed boxes labeled by the nursing homes for which the nurses worked. Each half of the index card also contained a sticker with that nurse's unique project number. Matching the two halves provided a way for the DONs to verify the attendance of the nurse at this event if in-service credit was given.

When the project was completed, the project manager brought a sealed box with entries for the $\$ 25$ gift card to each nursing home. Each DON unsealed the box and drew the name of her facility's winning participating nurse. The project manager also determined the nursing home with the greatest percentage of its nurses who had participated and provided the promised pizza party for those nurses approximately one month later.

\section{Project Funding and Budget}

The project manager applied for and received scholarship funds from the Nu Omicron chapter-at-large of Sigma (formerly Sigma Theta Tau International) in the amount of $\$ 500$. These funds were used to purchase supplies for recruitment efforts, materials created for the modules, supplies for demonstrations and practice, gift cards for the drawings and appreciation gifts for volunteers, prizes for the participants, and food for meals and snacks for the volunteers. The approximate cost for the project was $\$ 850$. The cost of materials beyond the Sigma funding was paid by the project manager.

Eight nursing instructors and experienced nurses graciously volunteered their time as observers for this project over two eight-hour days and one four-hour day. Based on the $\$ 30$ per hour rate paid by students who must make up missed clinical hours with an instructor from the school which collaborated in this project, their time could have cost at least $\$ 2,300$. Two student assistants also volunteered their time, potentially saving up to $\$ 160$. The host college allowed the use of their facilities (rooms, lights, restrooms, etc.) at no cost. The school of nursing agreed to the use of their nursing lab equipment with no charge as well.

\section{Summary of Intervention}

During the implementation of the project, most of the nurses arrived individually, and there was no waiting time to begin the skills demonstrations once the consent form was signed. Each nurse moved from one demonstration to the next and on to completing the pre-intervention quiz within about 30 minutes. Usually, only one or two nurses at a time were in the skills fair area working through the modules and skills stations, allowing each to progress at her own speed and with very little distraction. Some nurses chose to do both of the optional skills stations and both games to try earning extra points; most did not. Each nurse also completed the post-intervention skills demonstrations and quiz within 30 minutes. All participants enjoyed choosing from the selection of prizes based on their points earned. The total time spent by each nurse participating in this project was approximately two hours.

\section{Discussion of Findings}

Confidence and competence in clinical nursing skills can be increased through review and the use of multiple methods of instruction including hands-on practice (Park, 2018; Terry et al., 2018). The intervention included in this practice project used multiple methods of instruction and emphasized hands-on practice. The measures of clinical skills proficiency, skills demonstration checklists, and written quizzes, were statistically analyzed to determine whether the results would lend further support to these authors' conclusions. What follows is a discussion of the results, the implications for nursing practice in long-term care settings, and recommendations for a further study involving nursing home nurses and clinical skills competency. 


\section{Results}

During the three-day data collection process, 13 nurses from two nursing homes signed consent forms and participated in the project. Two were the directors of nursing from those facilities. As shown in Table 1, all 13 participants were female with a mean age range of 36-45+/- 0.91 years and eight of those were LPNs. The years of experience ranged from 10 months to 25 years, while the number of years working in a nursing home ranged from about one month to 33 years. Three nurses $(23 \%)$ had received training in techniques for the replacement of dislodged feeding tubes - one in a hospital, one by a physician identified by name, and one in another nursing home.

All except one participant indicated they completed online or in-service education required by the employer and shared or compared knowledge with other nurses to keep up to date on nursing knowledge or skills. Five nurses indicated that they subscribed to nursing magazines or journals either in hard copy or online, but only three of those marked that they read nursing magazines or journals. Two indicated that they read current nursing textbooks, one of whom had been a nurse for about ten months, but neither was currently taking classes toward another degree. Of the four who indicated that they were taking courses toward a higher degree, none marked that they read current nursing textbooks as a method to keep up to date on nursing knowledge or skills.

Table 1. Demographics $(\mathrm{N}=13)$

\begin{tabular}{|c|c|c|c|}
\hline \multicolumn{2}{|l|}{ Age } & \multicolumn{2}{|c|}{ Highest Education } \\
\hline $18-25$ yrs. & 0 & Diploma & 4 \\
\hline $26-35$ yrs. & 4 & Associates & 5 \\
\hline $36-45$ yrs. & 6 & Bachelors & 4 \\
\hline $46-55$ yrs. & 2 & Masters & 0 \\
\hline $56-65+$ yrs. & 1 & & \\
\hline \multicolumn{2}{|l|}{ Gender: } & \multicolumn{2}{|c|}{ License Type: } \\
\hline Male & 0 & LPN & 8 \\
\hline Female & 13 & $\mathrm{RN}$ & 5 \\
\hline \multicolumn{4}{|c|}{ Currently taking courses for a higher degree: } \\
\hline Yes & & 4 & \\
\hline No & & 9 & \\
\hline \multicolumn{4}{|c|}{ Has had training in G-tube replacement: } \\
\hline Yes & & 3 & \\
\hline No & & 10 & \\
\hline \multicolumn{4}{|c|}{ Methods used to stay up-to-date on nursing knowledge and skills } \\
\hline \multicolumn{2}{|c|}{$\begin{array}{l}\text { Subscribe to nursing magazines/journals (hard copy or } \\
\text { on-line) }\end{array}$} & 5 & \\
\hline \multicolumn{2}{|c|}{ Read nursing magazines/journals (hard copy or on-line) } & 3 & \\
\hline \multicolumn{2}{|c|}{ Attend nursing seminars or conferences } & 7 & \\
\hline \multicolumn{2}{|c|}{$\begin{array}{l}\text { Complete on-line or in-service education required by } \\
\text { employer }\end{array}$} & 12 & \\
\hline \multicolumn{2}{|c|}{ Share or compare knowledge with other nurses } & 12 & \\
\hline \multicolumn{2}{|c|}{ Read current nursing textbooks } & 2 & \\
\hline \multicolumn{2}{|c|}{ Other: "continuing college education" (written in) } & 1 & \\
\hline
\end{tabular}

Using IBM SPSS Statistics for Windows, version 25, paired $t$-tests (2-tailed) were performed on the pre-intervention scores and post-intervention scores for each checklist and the quiz to determine whether a significant change had occurred in these measures of skills proficiency. The mean on the quiz and both checklists 
was noted to be significantly less than the 76 to $78 \%$ passing score used by many schools of nursing for their students in a fundamentals course (see Table 2). However, the post-intervention mean on each was also significantly improved as noted by the $t$ scores and $p$ values. Cohen's $d$ was also calculated and demonstrated a large effect size for each measure.

Table 2. Results of $t$ tests and calculation of effect size for measures of proficiency

\begin{tabular}{llll}
\hline & Written Quiz & Tube Feeding & Catheter \\
\hline Pre-intervention & & Checklist & Checklist \\
\hline & $\mathrm{N}=13$ & $\mathrm{~N}=13$ & $\mathrm{~N}=13$ \\
\hline & $\mathrm{M}=.615$ & $\mathrm{M}=.562$ & $\mathrm{M}=.702$ \\
\hline Post-intervention & $\mathrm{SD}=.095$ & $\mathrm{SD}=.125$ & $\mathrm{SD}=.077$ \\
\hline & $\mathrm{N}=13$ & $\mathrm{~N}=13$ & $\mathrm{~N}=13$ \\
\hline & $\mathrm{M}=.769$ & $\mathrm{M}=.845$ & $\mathrm{M}=.889$ \\
\hline $\mathrm{t}$ & $\mathrm{SD}=.097$ & $\mathrm{SD}=.128$ & $\mathrm{SD}=.085$ \\
\hline $\mathrm{p}$ & $* 6.134$ & $* 6.312$ & $* 9.325$ \\
\hline Cohen's d & $<.000$ & $<.000$ & $<.000$ \\
\hline
\end{tabular}

* Significant $p$ value $<.001$ (2-tailed)

Pearson correlation coefficients were calculated to determine any relationships between level of education, years as a nurse, or years working in a nursing home and the pre-intervention or post-intervention checklists or quiz scores. For the pre-intervention tube feeding checklist scores and the highest level of education, a moderate positive correlation was found $(r(11)=.629, p<.05)(2$-tailed). For the post-intervention tube feeding checklist scores and years of working as a nurse, a moderate positive correlation was found $(r(11)=.600, p<.05)$ (2-tailed). No other significant relationships were identified.

All except one participant achieved an increase in score on the post-intervention quiz when compared to the pre-intervention quiz, including the one nurse who passed the pre-intervention quiz. A careful review of the quizzes of the one nurse whose score remained the same revealed that the same questions were incorrectly answered on both quizzes, though some incorrect answers were different. Five participants who had not achieved $76 \%$ or higher on the pre-intervention quiz achieved passing scores on the post-intervention quiz, while seven participants still did not achieve a passing score.

Before the implementation of this project, the 15-question pre-intervention form of the quiz was given to twelve nurses at another local nursing home that was not involved in the project. The results showed that only one nurse achieved a passing score of $76 \%$ or higher. An attempt was made to test for reliability by checking a Kuder-Richardson (KR) score. It was determined that the sample size was too small and the number of questions too few for the KR score to be useful.

Several nurses commented that they were glad they had come, that the review and practice were helpful, and that they had learned a lot. One self-reported she had only been working as a nurse for a short time and had not practiced catheterization since learning the skill in nursing school. She also stated that she had not catheterized a real patient yet. Both DONs said that they felt that this event was very worthwhile and that they also had learned from it. One DON verbalized her intention to make some changes related to gastrostomy tube care at her facility. Several observers reported noticing a great improvement in confidence and performance of the skills exhibited by the nurses following the intervention. One observer, who was asked to do both pre- and post-intervention observations of catheterizations on one day, reported being especially impressed by the improvement in the post-intervention performance of the nurses.

\section{Discussion of Results}

The hypothesis for this scholarly project was that the clinical skills proficiency of nursing home nurses would improve following an educational intervention emphasizing the hands-on practice of two clinical skills in a school of nursing lab. The results suggest that this hypothesis should be accepted based on the statistical data 
indicating significant increases in the two checklists and quiz scores evaluated. Comments by the observer who evaluated demonstrations of the urinary catheterization skill both pre- and post-intervention, and comments made by the participants, add supporting evidence that the educational intervention made a positive difference in the performance of the skills.

\subsection{Variances During Data Collection}

Hands-on practice and demonstrations of the two skills were critical parts of this project. The case was made that hands-on practice is necessary to maintain or increase the nurse's proficiency in the performance of clinical skills. However, unexpected variances occurred during pre-testing and the educational intervention that could have affected these results. One event cast doubt on the reliability of the method used to obtain the demonstration checklist scores. The other variances could have influenced the effect that emphasis on hands-on practice had on improving skills proficiency.

On the first day of the project, an observer checked with the project manager to verify that she had numbered the checklists correctly after observing the first nurse demonstrate the tube feeding skill. The observer reported that the nurse started with the first few steps on the tube feeding checklist, but then did the medication administration steps on the back side of the form before doing the tube feeding administration steps. This observer was initially unprepared, incorrectly numbered some steps while turning the page, and rewrote the corrected sequence immediately after the nurse completed the demonstration. The project manager determined that this was not incorrect, but a different order that should not ultimately affect the completion or scoring of the checklist. Observers on the second and third day were warned about this possibility during training before observations began. Errors in numbering may still have occurred due to turning the pages over multiple times, rather than just once, potentially affecting the reliability of the scores obtained.

One of the intended purposes of the educational intervention was that, after reviewing proper techniques in the modules, each nurse would practice each skill at least once at the skills stations provided. The project manager had anticipated that multiple nurses would be involved in the skills fair area to review and practice together, encouraging one another and engaging in peer evaluation during practice. However, the small number of nurses that did participate progressed through the skills fair individually, lacking the opportunity for collaborative learning and support. Had enough observers been recruited, they could have been used to oversee or guide those practicing. Even though the project manager specifically directed each nurse entering the skills fair to complete the hands-on practice of each skill, four did not. When reminded by the project manager before leaving the skills fair, one cited the need to finish and get to an appointment. One cited the need to finish and go pick up children from school. Two others were unwilling to comply with the request and did not give a specific reason.

Since four out of thirteen nurses did not participate in the hands-on practice of the two skills, the premise that hands-on practice is needed to help increase basic clinical skills proficiency could be questioned. The two modules reviewing urinary catheterization did not include the hands-on practice of any parts of that skill. Multiple opportunities for hands-on practice were available in the five modules reviewing techniques related to tube feeding. However, twelve out of thirteen nurses' scores for both the catheterization checklist and the tube feeding checklist increased, following the skills fair educational intervention. One could conclude that the hands-on practice of urinary catheterization was not necessary to improve proficiency in the performance of that skill. However, the question is whether those who did not practice that skill would have had a greater increase in their post-intervention checklist scores if they had practiced.

\subsection{Limitations}

The small number of project participants, only 13 nurses, and its narrow geographic location prevent generalization of the results beyond the local area nursing homes involved. The implementation of this project was much more complex and difficult than anticipated. Many factors negatively impacted the recruitment of nurse participants. Recruitment of observers also proved difficult.

\subsection{Small Sample Size}

When the project was first presented to each of the three DONs, their positive responses were encouraging. Two of the DONs wanted to make attendance mandatory for their nurses, expressing interest in the skills training offered for their nurses as wells as a desire to support the project. However, the consent form required voluntary participation. Although they encouraged their nurses to come to the recruitment presentation and encouraged them to participate in the project with offers of in-service credit, none of the three DONs was able to compensate their nurses financially for time spent participating. Nurses who participated had to be willing to come on their own time before or after scheduled work hours or on their days off. 
At one nursing home, the project manager had placed the advertising display board and sign-up sheets in a staff lounge as well as having placed flyers in nurses' mailboxes with the DONs approval. However, while retrieving the board and sign-up sheets, nurses were encountered who reported that they had not seen them because they seldom used the staff lounge and seldom checked their mailboxes. One reported that she had forgotten to sign up and was not sure that she could come.

The DON in the second nursing home stated she had no good location to put the display board and sign-up sheets after the recruitment presentations. She explained that she would keep them in her office and encourage or remind her staff to sign up. When the project manager returned to collect these items, no additional nurses had signed up. The DON also commented that her nurses might not have checked their mailboxes where she had placed flyers to remind them of the project.

At the third nursing home, recruitment presentations at staff meetings were scheduled by a DON who was no longer employed there when the presentations were given. The Assistant-DON approved placement of the display board and sign-up sheets following the presentation and was observed putting flyers into the nurses' mailboxes. However, she had resigned by the first day of the project, and none of the nurses from that facility who had signed up participated.

The decision was made to post the sign-up sheets for an additional week in more prominent locations, which allowed a few more nurses to be added. The project was initially shortened to two days instead of three because only one nurse signed up for the third day. However, at the end of the second day when the second DON had participated, she stated that she would encourage more of her staff to come if the third day could be reinstated; especially those who had signed up, but had not come. The change was made when enough observers agreed to help. An e-mail about the additional day was sent to the DON of the second nursing home to give an opportunity for other nurses from that facility to come as well. A phone call was made to the third nursing home to notify those nurses and to encourage the two who had signed up but not come.

\subsection{Difficulty Recruiting Observers}

Recruitment of observers was also difficult due to the timing of the project. Once the final dates were selected, several nursing instructors who had indicated willingness to help were unable to do so. The spring semester had just ended, and some instructors had vacations previously planned or were working at their secondary places of employment on those dates. Two instructors from another school of nursing and two experienced nurses were available and were willing to serve as observers.

When the third day of the project was added back onto the schedule, only three observers were able to help. One nursing instructor who had not helped during the first two days agreed and was trained to observe both pre- and post-intervention demonstrations of urinary catheterization for the three additional participants that day. The two others had already observed the tube feeding demonstrations the previous days.

\subsection{Potential Awareness Bias}

Attempts were made to keep the educational topics confidential before implementing this project. One of the DONs who participated was also the Project Mentor and knew that urinary catheterization was one of the skills involved. The project manager chose to tell her when the DON revealed that her nurse educator was planning a review of urinary catheterization during in-service training for her nurses shortly before this project was to begin. She agreed to have the topic changed and agreed not to tell her nurses.

Since the project took place over three days, the participating nurses could have had the opportunity to share what the project entailed with nurses who were still scheduled to come, or who were recruited by the DON for the third day. Except for the Project Mentor, the other DONs were told only that the project included the hands-on practice of two clinical skills. Each participating nurse was asked not to share what was involved until the project was completed.

\subsection{Test Anxiety}

Test anxiety could have affected the nurses' performance during demonstrations of the skills since they were not given advanced notice of this requirement during recruitment presentations. The project manager asked observers not to identify themselves as nurses or nursing instructors, and the observers' name tags contained only the word 'observer' and a first name. Observers were coached to encourage the nurses to take their time and do their best during skills demonstrations. Since a nurse's performance could also have been affected by distracting noises in the lab and the lack of complete privacy behind curtains that were not soundproof, nurses and observers were reminded to speak quietly as a courtesy to others being tested. 


\subsection{Timing of Post-Testing}

The post-intervention demonstrations and quiz were completed immediately after the skills fair educational intervention. Scores could have been influenced by the one-day design of the project. Results might have been different if the post-intervention demonstrations and quiz were done after a longer length of time, perhaps one week or more after the intervention.

\subsection{Implications for Practice}

The 15-question quiz pretested with 12 nursing home nurses in the fourth local nursing home revealed that only one nurse achieved a passing score of at least $76 \%$. Only one out of the 13 nurses from the two participating nursing homes achieved a passing score on the pre-intervention quiz during this project as well. A review of the pre-intervention scores for the catheterization and tube feeding skills demonstrations revealed three passing scores and one passing score, respectively. Although schools of nursing sometimes use $76 \%$ as a passing score for written exams, student nurses are expected to achieve much higher than the equivalent of $76 \%$ to demonstrate clinical skills proficiency successfully.

Based on the above results, the DONs of these facilities and others in the area should evaluate the clinical skills proficiency of all their nurses, for the two skills involved in this project and perhaps others. DONs outside of this area may also want to do the same. Because the particular skills used in this project may not be practiced on a regular basis, it is possible that a nurse's proficiency in the performance of these and other less regularly performed clinical skills could decline. A decrease in nurses' skills proficiency could place some nursing home residents at risk for infections and other potentially life-threatening complications and possibly lead to hospital readmission.

If clinical skills proficiency can decline, as discussed by Yang et al. (2015), but significant improvement in clinical skills proficiency can be seen after one hour of review including hands-on practice, DONs should consider two things. A review of at least some clinical skills should be included on their list of continuing education topics required each year. Hands-on practice, not just online programs, should be included in the methods used to provide review and updating of clinical skills for their nurses.

\section{Recommendations and Conclusion}

More studies need to be done to evaluate nursing home nurses' clinical skills proficiency and to discover the best methods for promoting maintenance or improvement in the performance of these skills. Nursing home administrators and DONs need to find ways to encourage their nurses to attend educational programs that include hands-on practice of clinical skills, i.e., paying them for the time and providing adequate staffing coverage.

DONs and nursing home administrators should develop partnerships or collaborate with local schools of nursing to engage the expertise of nurse educators, as has been recommended by other researchers (Bourbonniere \& Strumpf, 2008; Cooper et al., 2016; Dyck \& Kim, 2018; Fairchild et al., 2013; Murray, 2013). Together they could collaborate to develop skills review programs that are relevant to the needs of the nurses and their residents using the most current evidence-based practice. Equipment and materials might be made available by the schools of nursing for a more effective simulation of the skills chosen. In return, schools of nursing could increase recruitment opportunities by this exposure to their faculty and facilities.

This project should be repeated using what was learned in order to improve recruitment methods, including encouragement of DONs to pay for attendance or perhaps making attendance mandatory. The works of Bourbonniere and Strumpf (2008), Dyck and Kim (2018), and Murray (2013) support providing compensation, even as part of a benefits package, for nurses as well as flexible scheduling to allow for attendance at continuing education programs. As these authors also suggest, sites should be easily accessible and the material covered should be relevant to the nurses in order to encourage participation. Post-testing should be done both immediately after the educational intervention and again after a period of time has passed to validate retention of skills proficiency further.

Recruitment of nursing instructors also needs to be further improved in order to support the collaborative aspects of this kind of project. Schools of nursing and nursing homes could work together to provide compensation for the nursing instructors' time. Involving more nursing instructors and nursing home educators to help develop relevant modules, improve observation methods, and potentially teach at skill practice stations, should also be considered.

If nurses could be required or were paid to come to skills fair-style continuing education programs, groups of nurses could potentially participate in collaborative learning while reviewing modules together, helping each other to practice, and problem-solving together. Modules could be improved with additional video clips to 
illustrate content, or with interactive demonstrations of techniques by nurse educators to support a larger variety of learning styles. Ultimately the proficiency of clinical skills performance by nursing home nurses could be greatly enhanced, and the residents for whom they care would have their needs met with increased quality.

\section{References}

Adair, J., Hughes, L., Davis, S., \& Wolcott-Breci, M. (2014). Comparing new BSN RN self skills assessment to actual skills demonstration. Journal of Professional Nursing, 30(2), 180-184. https://doi.org/10.1016/j.profnurs.2013.09.009

American Nurses Association. (2014). Professional role competence: ANA position statement. Retrieved from https://www.nursingworld.org/practice-policy/nursing-excellence/official-position-statements/id/professiona l-role-competence/

American Nurses Association. (n.d.). Continuing education. Retrieved from https://www.nursingworld.org/continuing-education/

Battick, A. D. (2018). Enhancing urinary catheter skills among clinically practicing nurses. Doctoral Dissertation, Walden University. $\quad$ Retrieved from https://pqdtopen.proquest.com/doc/2026820763.html?FMT=AI

Belizario, S. M. (2015). Preventing urinary tract infections with a two-person catheter insertion procedure. Nursing, 45(3), 67-69. https://doi.org/10.1097/01.NURSE.0000460736.74021.69

Blumenstein, I., Shastri, Y. M., \& Stein, J. (2014). Gastroenteric tube feeding: Techniques, problems and solutions. World Journal of Gastroenterology, 20(26), 8505-8524. https://doi.org/10.3748/wjg.v20.i26.8505

Bourbonniere, M., \& Strumpf, N. E. (2008). Enhancing geriatric nursing competencies for RNs in nursing homes. Research in Gerontological Nursing, 1(3), 171-175. https://doi.org/10.3928/00220124-20091301-02

CareCEU's. (2018). NAB CEUS. Retrieved from https://www.careceus.com/ceu-categories/nab-ceus.php

Castle, N., Engberg, J. B., Wagner, L. M., \& Handler, S. (2017). Resident and facility factors associated with the incidence of urinary tract infections identified in the Nursing home minimum data set. Journal of Applied Gerontology, 36(2), 173-194. https://doi.org/10.1177/0733464815584666

Competent. (2018). In Merriam-Webster's online dictionary. Retrieved from https://www.merriam-webster.com/dictionary/competent

Cooper, E., Spilsbury, K., McCaughan, D., Thompson, C., Butterworth, T., \& Hanratty, B. (2016). Priorities for the professional development of registered nurses in nursing homes: A Delphi study. Age and Ageing, 46(1), 39-45. https://doi.org/10.1093/ageing/afw160

Draganov, P. B., de Carvalho Andrade, A., Neves, V. R., \& Sanna, M. C. (2013). Andragogy in nursing: A literature review. Investigacion \& Educacion En Enfermeria, 31(1), 86-94. Retrieved from http://www.redalyc.org/articulo.oa?id=105226364010

Dyck, M. J., \& Kim, M. J. (2018). Continuing education preferences, facilitators, and barriers for nursing home nurses. Journal of Continuing Education in Nursing, 49(1), 26-33. https://doi.org/10.3928/00220124-20180102-07

EasyCEU. (n.d.). All courses by name. Retrieved from http://www.easyceu.com/all-courses

Education Interface. (2014). EI courses. Retrieved from https://www.educationinterface.com/continuing-education/

Fairchild, R. M., Everly, M., Bozarth, L., Bauer, R., Walters, L., Sample, M., \& Anderson, L. (2013). A qualitative study of continuing education needs of rural nursing unit staff: The nurse administrator's perspective. Nurse Education Today, 33(4), 364-369. https://doi.org/10.1016/j.nedt.2012.05.023

Hayes, K. D., \& Hayes, D. D. (2018). Best practices for unclogging feeding tubes in adults. Nursing, 48(6), 66. https://doi.org/10.1097/01.NURSE.0000532744.80506.5e

Indiana General Assembly. (2016a). 410 IAC 16.2 Health facilities; Licensing and operational standards. Retrieved from http://www.in.gov/legislative/iac/T04100/A00162.PDF

Indiana General Assembly. (2016b). 848 IAC 2 Standards for the competent practice of registered and licensed practical nursing. Retrieved from http://www.in.gov/legislative/iac/T08480/A00020.PDF

Indiana Professional Licensing Agency \& Indiana State Board of Nursing. (2018). Continuing education 
requirements. Retrieved from https://www.in.gov/pla/2492.htm

Institute of Medicine (U.S.). (2001). Crossing the quality chasm: A new health system for the 21st century. Washington, DC: National Academy Press. https://doi.org/10.17226/10027

Jump, R. L. P., Crnich, C. J., Mody, L., Bradley, S. F., Nicolle, L. E., \& Yoshikawa, T. T. (2018). Infectious diseases in older adults of long - term care facilities: Update on approach to diagnosis and management. Journal of the American Geriatrics Society, 66(4), 789-803. https://doi.org/10.1111/jgs.15248

Kaur, J., Stone, P. W., Travers, J. L., Cohen, C. C., \& Herzig, C. T. A. (2017). Influence of staff infection control training on infection-related quality measures in US nursing homes. American Journal of Infection Control, 45(9), 1035-1040. https://doi.org/10.1016/j.ajic.2017.04.285

Knowles, M. S., Holton, E. F., \& Swanson, R. A. (2005). The adult learner: The definitive classic in adult education and human resource development (6th ed.). Retrieved from https://proquest.libguides.com/ebookcentral

Kohn, L. T., Corrigan, J. M., \& Donaldson, M. S. (2000). To err is human: Building a safer health system. Washington, DC: National Academy Press. https://doi.org/10.17226/9728

Leigh, K., Whitted, K., \& Hamilton, B. (2015). Integration of andragogy into preceptorship. Journal of Adult Education, 44(1), 9-17. Retrieved from https://files.eric.ed.gov/fulltext/EJ1072924.pdf

Lippincott Nursing Center. (2018). Nursing continuing education activities: CEConnection. Retrieved from https://www.nursingcenter.com/continuing-education

Lohmann, K., Gartner, D., Kurze, R., Schösler, T., Schwald, M., Störzinger, D., Hoppe-Tichy, T., \& Seidling, H. M. (2015). More than just crushing: A prospective pre-post intervention study to reduce drug preparation errors in patients with feeding tubes. Journal of Clinical Pharmacy and Therapeutics, 40(2), 220-225. https://doi.org/10.1111/jept.12250

Lohsiriwat, V. (2013). Percutaneous endoscopic gastrostomy tube replacement: A simple procedure?. World Journal of Gastrointestinal Endoscopy, 5(1), 14-18. https://doi.org/10.4253/wjge.v5.i1.14

McDevitt, D., \& McDevitt, M. F. (2015). Yes or no? Pretesting indwelling urinary catheter balloons. Nursing Made Incredibly Easy, 13(6), 14-15. https://doi.org/10.1097/01.NME.0000471847.76001.5b

McGinnis, C. (2013). Replacing gastrostomy tubes. Critical Care Nurse, 33(5), 75-76. https://doi.org/10.4037/ccn2013683

Mody, L., Meddings, J., Edson, B. S., McNamara, S. E., Trautner, B. W., Stone, N. D., \& Saint, S. (2015). Enhancing resident safety by preventing healthcare-associated infection: A national initiative to reduce catheter-associated urinary tract infections in nursing homes. Clinical Infectious Diseases: An Official Publication of the Infectious Diseases Society of America, 61(1), 86-94. https://doi.org/10.1093/cid/civ236

Murray, R. R. (2013). A quantitative analysis of factors that influence participation in continuing education among nurses employed in long-term care facilities. Doctoral Dissertation, Available from ProQuest Dissertations \& Theses Global.

Nurse.com: On Course Learning. (2018). Retrieved from https://www.nurse.com/

Parchen, D. A., Phelps, S. E., Johnson, E. M., \& Fisher, C. A. (2016). Improving efficiency using a hybrid approach: Revising an IV/blood workshop in a clinical research environment. Journal for Nurses in Professional Development, 32(3), 144-149. https://doi.org/10.1097/NND.0000000000000252

Park, S. (2018). Effects of an intensive clinical skills course on senior nursing students' self-confidence and clinical competence: A quasi-experimental post-test study. Nurse Education Today, 61, 182-186. https://doi.org/10.1016/j.nedt.2017.11.028

Perry, A. G., Potter, P. A., \& Ostendorf, W. (2018a). Clinical nursing skills \& techniques (9th ed.). St. Louis, MO: Elsevier.

Perry, A. G., Potter, P. A., \& Ostendorf, W. (2018b). Skills performance checklists for Clinical nursing skills \& techniques (9th ed.). St. Louis, MO: Elsevier.

Peterson, A. M. (2016). Aspiration pneumonia in the elderly tube fed patient -- avoidable or unavoidable: Considerations for the LNC. Journal of Legal Nurse Consulting, 27(3), 36-40. Retrieved from http://www.aalnc.org/d/do/927

Polit, D. F., \& Beck, C. T. (2014). Essentials of nursing research: Appraising evidence for nursing practice. 
Philadelphia, PA: Wolters Kluwer/Lippincott Williams \& Wilkins.

Posthauer, M. E., Dorner, B., \& Friedrich, E. K. (2014). Enteral nutrition for older adults in healthcare communities. Nutrition in Clinical Practice, 29(4), 445-458. https://doi.org/10.1177/0884533614541482

Pretoruis, L., Van Dyk, A., Small, L. F., \& Amukugo, H. J. (2016). An educational programme to facilitate critical thinking within the nursing perspective. International Journal of Advanced Nursing Studies, 5(2), 212-221. https://doi.org/10.14419/ijans.v5i2.6556

Proactive Medical Review. (2018). SNF competency tool kits-now available!. Retrieved April 26, 2018, from http://www.proactivemedicalreview.com/snf-compentency-tool-kits-now-available/

Proficient. (2018). Merriam-Webster's online dictionary. Retrieved from https://www.merriam-webster.com/dictionary/proficient

Rahnemai-Azar, A. A., Rahnemaiazar, A. A., Naghshizadian, R., Kurtz, A., \& Farkas, D. T. (2014). Percutaneous endoscopic gastrostomy: Indications, technique, complications and management. World Journal of Gastroenterology, 20(24), 7739-7751. https://doi.org/10.3748/wjg.v20.i24.7739

Reform of requirements for long-term care facilities. (2016). Medicare and Medicaid Programs; Reform of Requirements for Long- Term Care Facilities. Federal Register, 81(192), 68688-68872. https://www.gpo.gov/fdsys/pkg/FR-2016-10-04/pdf/2016-23503.pdf

Registered Nurse RN. (2017, April 5). Do not crush medications mnemonic: Crushing medications for tube feeding. Retrieved from https://www.youtube.com/watch?v=kT30M7mKqEA

Relf, B., \& Burgess, C. (2014). The challenges of curriculum design in a large enabling pre-nursing open access course. Foundation and Bridging Educators of New Zealand (FABENZ), Tauranga, New Zealand, 4-5. Retrieved from http://fabenz.org.nz/wp-content/uploads/2016/01/REL14015-paper.pdf

Relias. (2018). Course library samples. Retrieved from https://www.relias.com/product/course-library

Rhone, C., Breiter, Y., Benson, L., Petri, H., Thompson, P., \& Murphy, C. (2017). The impact of two-person indwelling urinary catheter insertion in the emergency department using technical and socioadaptive interventions. Journal of Clinical Outcomes Management, 24(10), 451-456. Retrieved from https://www.mdedge.com/jcomjournal/article/149684/emergency-medicine/impact-two-person-indwelling-u rinary-catheter

Roulet, L., \& Benoit, E. (2016). Letter: Medication administration via enteral feeding tube. International Journal of Clinical Pharmacy, 38(4), 747-748. https://doi.org/10.1007/s11096-016-0314-5

Scheckel, M. (2016). Designing courses and learning experiences. In D. M. G. Billings, \& J. A. Halstead (Eds.), Teaching in nursing: A guide for faculty (pp. 159-185). St. Louis, MO: Elsevier.

Schneider, M. A., \& Ruth-Sahd, L. A. (2015). Fundamentals: Still the building blocks of safe patient care. Nursing, 45(6), 60-63. https://doi.org/10.1097/01.NURSE.0000464987.77315.76

Sheff, Z. T., Zollinger, T. W., Harper, K., Crawford, E. K., \& Buente, B. (2013). 2012 Indiana licensed practical nurse licensure survey report. Retrieved from https://www.ic4n.org/wp-content/uploads/2014/01/2012_Indiana_LPN_Licensure_Survey_Report.pdf

Shepherd, M. L., \& Harris, M. L. (2016). Advancing a Magnet culture in the midst of change. Journal of Nursing Education \& Practice, 6(6), 17-27. https://doi.org/10.5430/jnep.v6n6p17

Shipley, K., Gallo, A.-M., \& Fields, W. (2016). Is your feeding tube clogged? Maintenance of gastrostomy and gastrojejunostomy tubes. Medsurg Nursing, 25(4), 224-228. Retrieved from https://www.amsn.org/professional-development/periodicals/medsurg-nursing-journal

Simons, S., \& Remington, R. (2013). The percutaneous endoscopic gastrostomy tube: A nurse's guide to PEG tubes. Medsurg Nursing, 22(2), 77-83. Retrieved from http://digitalcommons.framingham.edu/cgi/viewcontent.cgi?article $=1023 \&$ context=nurs_facpub

Spies, C., Seale, I., \& Botma, Y. (2015). Adult learning: What nurse educators need to know about mature students. Curationis, 38(2), 1-7. https://doi.org/10.4102/curationis.v38i2.1494

Terry, V. R., Terry, P. C., Moloney, C., \& Bowtell, L. (2018). Face-to-face instruction combined with online resources improves retention of clinical skills among undergraduate nursing students. Nurse Education Today, 61, 15-19. https://doi.org/10.1016/j.nedt.2017.10.014

U. S. Department of Health \& Human Services, Agency for Healthcare Research and Quality. (2017a). AHRQ 
safety program for long-term care: Preventing CAUTI and other HAIs: Final report. Retrieved from https:/www.ahrq.gov/sites/default/files/wysiwyg/professionals/quality-patient-safety/quality-resources/tool s/cauti-ltc/modules/final-report.pdf

U. S. Department of Health \& Human Services, Agency for Healthcare Research and Quality. (2017b). Guide to implementing a program to reduce catheter-associated urinary tract infections in long-term care. Retrieved from

https:/www.ahrq.gov/sites/default/files/wysiwyg/professionals/quality-patient-safety/quality-resources/tool s/cauti-ltc/modules/ implementation/implementing-guide.pdf

U. S. Department of Health \& Human Services, Agency for Healthcare Research and Quality. (2017c). Guide to sustaining a program to reduce catheter-associated urinary tract infections in long-term care. (AHRQ publication no. 16(17)-0003-6-EF). Retrieved from https:/www.ahrq.gov/sites/default/files/wysiwyg/professionals/quality-patient-safety/quality-resources/tool s/cauti-ltc/modules/ sustainability/sustaining-guide.pdf

U. S. Department of Health \& Human Services, Centers for Medicare \& Medicaid Services. (n.d.). Nursing home compare. Retrieved from https:/www.medicare.gov/nursinghomecompare/

U. S. Department of Health \& Human Services, Centers for Medicare \& Medicaid Services. (2015). Nursing home data compendium $2015 \quad$ edition. $\quad$ Retrieved from https:/www.cms.gov/Medicare/Provider-Enrollment-and-Certification/CertificationandComplianc/Downloa ds/nursinghomedatacompendium_508-2015.pdf

U. S. Department of Health \& Human Services, Centers for Medicare \& Medicaid Services. (2018). Minimum $\begin{array}{llllll}\text { data set } & 3.0 & \text { public } & \text { Reports. } & \text { from }\end{array}$ https:/www.cms.gov/Research-Statistics-Data-and-Systems/Computer-Data-and-Systems/Minimum-Data-S et-3-0-Public-Reports/Minimum-Data-Set-3-0-Frequency-Report.html

Vata, Inc. (n.d.). Seymour II ${ }^{T M}$ wound care model--0910. Canby, OR: Vata, Inc.

Wilson, B., Harwood, L., \& Oudshoorn, A. (2015). Understanding skill acquisition among registered nurses: The 'perpetual novice' phenomenon. Journal of Clinical Nursing, 24(23-24), 3564-3575. https://doi.org/10.1111/jocn.12978

Yang, Y. O., Kim, M., Park, K.-Y., \& Yang, J.-H. (2015). Factors influencing the confidence in core clinical skills among hospital nurses. International Journal of Nursing Practice, 21(6), 831-838. https://doi.org/10.1111/ijn.12310

\section{Copyrights}

Copyright for this article is retained by the author(s), with first publication rights granted to the journal.

This is an open-access article distributed under the terms and conditions of the Creative Commons Attribution license (http://creativecommons.org/licenses/by/4.0/). 